\title{
NICOLA PASQUALICCHIO, «Le tour du théâtre». Jean \\ Tardieu drammaturgo
}

\section{Stefano Genetti}

\section{OpenEdition}

\section{Journals}

\section{Edizione digitale}

URL: https://journals.openedition.org/studifrancesi/44238

DOI: 10.4000/studifrancesi.44238

ISSN: 2421-5856

\section{Editore}

Rosenberg \& Sellier

\section{Edizione cartacea}

Data di pubblicazione: 1 juin 2021

Paginazione: 246-247

ISSN: 0039-2944

\section{Notizia bibliografica digitale}

Stefano Genetti, «Nicola Pasoualicchio, «Le tour du théâtre». Jean Tardieu drammaturgo», Studi Francesi

[Online], 193 (LXV | I) | 2021, online dal 01 juillet 2021, consultato il 15 octobre 2022. URL: http:// journals.openedition.org/studifrancesi/44238; DOI: https://doi.org/10.4000/studifrancesi.44238

Questo documento è stato generato automaticamente il 15 octobre 2022.

\section{(c) $($ ) $\odot \odot$}

Creative Commons - Attribuzione - Non commerciale - Non opere derivate 4.0 Internazionale - CC BYNC-ND 4.0

https://creativecommons.org/licenses/by-nc-nd/4.0/ 


\title{
NICOLA PASQUALICCHIO, «Le tour $d u$ théâtre». Jean Tardieu drammaturgo
}

\author{
Stefano Genetti
}

\section{NOTIZIA}

Nicola PASQUAlicchio, «Le tour du théâtre». Jean Tardieu drammaturgo, Verona, Fiorini, 2019, «La musa critica», 149 pp.

1 «Telle est la loi de mon théâtre», scriveva Tardieu a proposito di una passione a due facce coltivata in segreto fin da bambino: «à l'endroit les villes et les paysages, la terre et le ciel, tout est peint, simulé à merveille. À l'envers, l'artisan de ce monde illusoire est soudain démasqué, car son œuvre, si ingénieuse soit-elle, révèle, par transparence, la misère des matériaux qui lui ont servi à édifier ses innombrables "trompe-l'œil"» («Mon théâtre secret», in L'amateur de théâtre, Gallimard, 2003, p. 31). Analogia pittorica, demistificazione dell'illusione mimetica, metateatralità "artigianale", ma anche ricercata musicalità, onirismo perturbante e porosità dei confini tra lirica e dialogo teatrale: sono queste alcune delle dominanti dell'opera di un drammaturgo che coniuga pratica e riflessione teorica, come sottolinea Anna Maria Babbi nella sua «Premessa» alla monografia di Nicola Pasqualicchio, cui si devono vari lavori sulle drammaturgie del fantastico, su Craig, Artaud, Genet e altri. Nel rifare il "giro" del teatro di Tardieu - il titolo riprende un'espressione utilizzata dallo scrittore in una lettera a Martin du Gard (p. 72) - lo studioso ne offre una visione d'insieme allo stesso tempo agile e approfondita, basata anche sui manoscritti conservati all'IMEc e sensibile alla dimensione performativa delle pièces, nonché alle discrepanze tra la produzione teatrale e l'autocommento che la accompagna, influenzandone la ricezione.

2 Bipartito, il volume si apre con un articolato capitolo - «Tardieu e il teatro: la rivelazione tardiva di una vocazione precoce» - sul lungo periodo che precede la pubblicazione, nel 1946, del primo testo teatrale (Les dieux inutiles) e la rappresentazione, tre anni dopo, ad Anversa, di Qui est là?, la prima pièce a essere messa 
in scena. Un poeta ormai affermato approda così al teatro: tuttavia, gli inediti «Jeux puérils» e abbozzi giovanili, dalla moliéresque farsa in versi Le Magister malgré lui alla trasognata e straniante gestualità di Le prix de la réalité (primissimi anni Venti), testimoniano già della propensione al gioco con le parole e con la punteggiatura e alla ricerca di contrasti tonali quali il «ridicule touchant» (p. 19). Parimenti, nelle prime dichiarazioni teoriche si manifesta, da un lato, l'attenzione agli aspetti scenotecnici della rappresentazione e all'interazione fra le arti che lo spazio teatrale instaura; dall'altro, la tendenza alla stilizzazione e la diffidenza verso una concezione mimetica del «valore veritativo del teatro» (p. 23), stimolando un parallelo con Pirandello (pp. 27-29). Se, dal Malade imaginaire cui il piccolo Tardieu assiste col padre alla ComédieFrançaise ai Contes d'Hoffmann messi in scena da Max Reinhardt a Berlino nel 1932, il vissuto di spettatore incide profondamente sul suo interesse per il teatro, quest'ultimo si esplica negli anni Quaranta nell'attività di traduttore (Ifigenia in Tauride e Pandora di Goethe) e di collaboratore dei periodici di sinistra «Ce soir» e "Action» in qualità di recensore che ammira le rivisitazioni dei classici mostrandosi attento alle innovazioni drammaturgiche e al profilarsi, nel teatro contemporaneo, di una tragicità anti-eroica, desublimata. Ma è nelle vesti di direttore, fin dall'immediato dopoguerra, del Club d'Essai, prestigioso laboratorio multidisciplinare dove si esplorano le possibilità tecnologiche e artistiche della radio, che Tardieu si dedica in maniera continuativa alla scrittura teatrale. Pur essendo i suoi radiodrammi - peraltro adattabili alla scena, diversamente da quelli di Beckett analizzati da N. Pasqualicchio in Il sarto gnostico. Temi e figure del teatro di Beckett (Ombre corte, 2006) - perlopiù posteriori, l'esperienza radiofonica, e in particolare la cooperazione tra compositori e drammaturghi, è alla base di un trattamento eminentemente vocale e musicale della parola teatrale, "così orientata verso la preminenza della componente sonora da pensare di trasformare i drammi in concerti di parole» (p. 57).

Oltre ad alimentare l'osmosi tra poesia e drammaturgia - si pensi ai Poèmes à jouer -, la ricerca di un "teatro per l'orecchio" si riversa in intitolazioni quali Conversationsinfonietta e La sonate des trois Messieurs, ou Comment parler musique o nella comparazione fra le études tramite cui l'autore perlustra le componenti della teatralità e il «clavecin bien tempéré» di Bach (nell'avant-propos del 1966 al Théâtre de chambre). Ora, al proliferare degli elementi paratestuali - sottotitoli, indicazioni di genere, raggruppamenti formali, di intonazione o tematici - e all'«inquietudine classificatoria» che vi si palesa è dedicata buona parte del secondo capitolo: «Un teatro senza eguali». Se confrontata con la sfuggente diversità delle singole pièces, la sistematizzazione del corpus proposta da Tardieu nell'edizione in quattro volumi per la collection «Blanche» di Gallimard (1955-1984) e poi variata nell'edizione «Folio» in tre volumi (1987-1993: La comédie du langage, La comédie de la comédie affiancata dalla Comédie des arts e La comédie du drame) risulta, non fuorviante, poiché mette in rilievo ad esempio la preminenza dell'oggetto scenico sul sujet, sull'argomento, ma pur sempre parziale. Nella sua tendenza «a ridiscutersi più che ad assestarsi», lo sforzo tassonomico si rivela «il prodotto di un'operazione creativa più che ordinatrice» (p. 95), rivelatrice dell'irriducibile «fantasia "sperimentale"» (p. 81) che è la cifra di una drammaturgia consapevole della propria portata innovativa, così come la brevità, «ben lungi dall'essere un occasionale strumento, è la misura (quantitativa e qualitativa) del teatro di Tardieu, è il suo ritmo e il suo respiro, non è accidente ma sostanza della sua ispirazione» (p. 82). 
4 Evidenziando l'apporto di Tardieu al rinnovamento del panorama teatrale a partire dagli anni Cinquanta, l'A. individua alcune linee di continuità che, fin dalle prime esquisses, caratterizzano tutta l'opera di Tardieu. Vi rientrano lo sfruttamento parodico della situazione didattica - a lezione dal professor Froeppel - o il motivo ricorrente dell'intercambiabilità di mestieri e ruoli: Un mot pour autre, Un geste pour autre e così via. Se applicato al ruolo e al mestiere di figurante (p. 123), questo dispositivo si carica di valenze esistenziali rivelatrici di una Weltanschauung venata di umorismo ma non per questo meno cupa. Una rilettura della trilogia di microdrammi La triple mort du client, dove, complice un intermediario inanimato, un pretesto prosaico dà luogo a una meditazione metafisica sulla morte, e di La jeune et fille et le haut-parleur, monologo cruel col quale si conclude La comédie du drame inaugurata da La cité sans sommeil, finzione fantastique e distopica, corregge il longevo malinteso che fa di Tardieu un drammaturgo "lieve", accentuando invece i tremolii del senso che, fosse anche a partire da una costrizione formale o da una sorridente trovata, incessantemente trapelano da quella che, in quarta di copertina, viene definita «la tragicommedia di un universo instabile». 